\title{
THE ASSOCIATION OF ACCIDENT SEVERITY AND FREQUENCY WITH VEHICLE AGE*
}

\section{A Study in Three Michigan Counties for the Period 1 January to 30 September, 1966}

\author{
JOSEPH W. LITTLE \\ University of Florida \\ William K. HaLl \\ Highway Sately Research Institute. Lniversity of Michigan \\ (Recoived A Itri 1969: revived 3 Octoher 1969)
}

INTRODUCTION

"DETERIORATION OF a vehicle with time is inescapable, whether from normal wear, abuse, defective construction, improper maintenance, poor quality of original or repair parts, inadequate skill of mechanics or other factors. With the deterioration of such components as brakes, steering systems, and tires, the chances of the vehicle becoming involved in a crash increase." This assertion was made by the Secretary of Transportation in his July 1968 report to the Congress (1968) and it reflects the intuitive approach taken by some highway safety advocates. They believe vehicle aging leads to deterioration and that deterioration makes older vehicles, compared with new ones, more prone to crashes and more susceptible to damages when crashes occur. As a result of both, they argue, older vehicles contribute disproportionately to highway losses.

Since the recommendations of the above report will influence highway safety countermeasures, it is important that the underlying hypotheses be carefully investigated. At the time this study was begun (more than a year before the Secretary's report was released). this question was asked: Are measurable crash phenomena associated with aging, and. if so, how may these be influenced by countermeasures such as motor vehicle inspection? Since past studies did not adequately examine the questions, this project was designed to investigate certain relevant factors in more detail.

THE EXPERIMENTAL PLAN

Two basic questions have been asked in this project. First. is the severity of a given crash a function of vehicle age? Second. is the probability of crash (of given severity) a function of vehicle age? (The statistical treatment of these questions is described elsewhere in this report.)

Simple analyses seem to show a positive correlation between increasing crash rates and increasing vehicle age. Schreiber and Schechter (1962) produced data (from their own study and two earlier ones) first indicating that the number of crashes per mile travelled increases as vehicle age increases. However, when they subjected their data to further

\footnotetext{
* This study was sponsored by The University of Michigan Highway Satety Research Institute. However. the conclusions are those of the authors and should not be interpreted as representing the views of either the University or the Institute.
} 
analysis this positive correlation was shown to be an artifict of their analytical method. and a tinal analysis indicated no discernible correkation between the wo variables. It should be noted that their study involved a teec of cars in which the miles actually travelled by individual vehicies were measurable.)

The approach taken here differs from earlier studies primarily in the more detailed classification of crashes and in the techniques used for developing sample and control populations. In the sample populations obtained for earlier studies. erashes were treated as a single criterion without regard to severity. To cetermine whether certain aging-crash characteristics might have been masked by this broad treatment. the crashes in the present study were categorized according to severity: fatal crashes. severe personal injury crashes. and minor crashes. (The classification procedures are described in a later section.)

The problem of controlling for exposure to crash-producing sttuations always creates uncertainties in studies of this type. Earlier investigators have used "miles travelled" as the relevant parameter. However. Schreiber and Schechter point out that the risk of crashes also varies markedly as a function of driving conditions.

In this study. exposure has been controlled simply by assuming that the crash risk for vehicles of a given age is directly related to the proportion of the total vehicle population represented by the number of vehicles of that age. This eliminates the necessity of obtaining mileage data (an important advantage, since obtaining reliable mileage data for vehicles in the general population is difficult).

\section{SA WPLING NETHODOLOGY}

Choosing the overall vehicle-age distributions as the control parameter raises the difficult problem of insuring that the crash-vehicle sample is drawn from the same population as is the control sample. Despite their large numbers when integrated over time and space, the number of crashes occurring within a given time period and within a given geographic area is small. Similarly, vehicle-age distribution is a function of both time and space. For example. a vehicle involved in a crash in Detroit. Michigan. in January is almost certain to have come from a significantly different vehicle population than a vehicle involved in a crash in Traverse City. Michigan, in August.

In order to control this problem. crash data were drawn from limited geographic areas during a given fixed time period. Three Michigan counties. Washtenaw. Kalamazoo, and Muskegon, were selected as the area laboratories to test the geographic extent of any patterns which might emerge. Washtenaw County, the home county of The Highway Safety Research Institute, where the research was conducted. offers a mix of rural and town driving. with a single large-town complex (Ann Arbor - Ypsilanti) embedded in an otherwise rural small-town county. The county is crossed east to west (I-94 and U.S. 12) and north to south (U.S. 23) by major traffic arteries. Kalamazoo and Muskegon Counties were selected because their geographical and population characteristics seem to match those of Washtenaw County adequately; both counties are predominantly rural, each containing a single large town (Kalamazoo and Muskegon, respectively). Kalamazoo County is crossed east to west (I-94) and north to south (U.S. 31) by major arteries, and Muskegon County is crossed north to south by a major artery (U.S.-31) and is the western terminus of another $(\mathrm{I}-96)$.*

\footnotetext{
"Of these trattic artertes, 1-44. which is a major link between Detroit and Chicago, is probably the most heavily travelled. I-96: linking Detroit, Lansing. and Grand Rapids. probably stands second. U.S.-23. being part of the major north-south artery in Michigan. carries much holiday iraffic and is a link between the industrial complex around Saginaw and Bay City and lower southeast Michigan. However. the most heavily travelled portions of U.S:-23 are probably north of Washtenaw County
} 
For comparison. the relevant populations from each of the counties and their major cities are shown in Table 1.

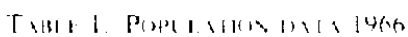

\begin{tabular}{|c|c|c|c|c|}
\hline Cinunly & Population* & $\begin{array}{l}10.11 \\
\text { woh:cles }\end{array}$ & Major cily & Population \\
\hline Rialatmikono & $164.71=$ & $7 . .21$ & hitlamaroo & $x=18 \times 4$ \\
\hline Muskentun & 149.44 & $0: 584$ & Bustionn & $40+5:$ \\
\hline Wasticinas & $172+40$ & Sid. 50 : & Ann trbor & $\theta=i+1)$ \\
\hline
\end{tabular}

The period between January 1. 1966 and September 30.1966 . Was selected as the study time trame. (The September 30 cut-off eliminated 1967 vehicles introduced about October 1. 1966.)

During the study time frame. legally reportable crashes were those " in which any person is killed or injured or in which damage in excess of $\$ 100.00$ is done to the property of any one person ...." Police officers investigate and report all eligible crashes called to their attention. and original copies of the reports are maintained in the Michigan State Police central record files located in East Lansing. Michigan. The reports are filed chronologically by county, allowing tor straightforward procedures in sampling from the relevant crash populations.

This study is limited strictly to four-wheeled passenger automobiles (trucks. buses. and cycles are excluded. as are automobiles involved in accidents with pedestrians). The only parameters of concern are model year (the vehicle age parameter) and crash severity.

Obtaining control samples describing (in terms of vehicle age distributions) the populations from which the crash samples were drawn is difficult. since the parent vehicle populations were continually changing in make-up throughout the study time frame. Consequently, the distribution representing the aggregate population cannot be measured at an instant in time. but instead must be derived. Accordingly. procedures were developed for deriving such distributions from published passenger car registration records. These procedures and the problems encountered are vital to the validity of this work: they are described in Appendix A.

\section{THE DATA}

Devising a crash-severity classification scheme for this study was aided materially by the uniform accident reporting form in use throughout Michigan. Officers investigating accidents estimate and record the extent of injuries sustained by every occupant of each vehicle involved in a crash. Injuries are reported according to tive discrete severity levels ranging from fatal injury to no injury. Although police officers gain expertise in evaluating injuries. neither their training nor their working conditions make for accurate medical judgments. What may appear to be a serious injury at the accident scene may prove to be minor and vice versa. However. the end points to the injury spectrum - fatal injury and no injury -are relatively objective. (When deaths occur after removial from the scene, the

\footnotetext{
* Data Source: 1967 edition Michigan Official Highway Map (1960 census or later).

$\div$ Original registrations of 1966 series license plates (valid 11 | 65 through 10 31 66). Datal soures: Michigan Dopartment of State.

+ Sec Michigan Venicle Code (Revision ol 1465 ). Section 200. Minimum reporlable property damage has since increased to $\$ 200$.
} 
on-the-spot report is changed accordingly.) To reduce evaluation crrors and to increase the sizes of the samples in each category the data were re-cast into only three severity classes:

Class A: Fatal injury crashes. These are hereafter referred to as fatal crashes

Class B: Severe personal injury crashes. These are hereafter referred to as severe crashes.

Class C: Winor personal injury or only property damage crashes. These are hereafter referred to as minor crashes.

Injuries. of course. occur only to people and not to the vehicles themselves. except in terms of property damage. Therefore. the following measure was developed for associating vehicles with crash severity: each vehicle was assigned severity class $A, B$, or C according to the most severe injury sustained by any occupant of the vehicle. To illustrate: if a three-car crash produced one person killed in one vehicle. one person injured seriously in the second. and only property damage to the third, then the three vehicles would receive severity classifications $A$. B, and $C$, respectively. (In an alternative scheme, every rehicle was classified according to the most severe injury to any occupant of any car in the crash. Since analyses of the data grouped in that fashion suggest no different inferences. they have been omitted from this report.)

All fatal crashes occurring within the study time frame and about ten per cent of all reported non-fatal crashes are included in the study. Because non-fatal accident reports are filed chronologically by township in each county, the following sampling technique was used. The first record in each to wnship and every tenth record thereafter were sampled, and if fewer than 10 records remained in a file after the last examined, no more were selected from it. The procedure was designed to produce a sample of slightly more than ten per cent of all non-fatal crashes.

Tables 2, 3. and 4. present data* from each of the three study counties. and Table 5 presents all the data logether. The following data are included in each table:

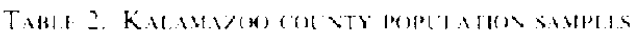

\begin{tabular}{|c|c|c|c|c|}
\hline \multirow[b]{2}{*}{$\begin{array}{l}\text { Model } \\
\text { yeur }\end{array}$} & \multicolumn{3}{|c|}{ Cralsines } & \multirow[b]{2}{*}{$\begin{array}{c}\text { Control } \\
\text { Population }\end{array}$} \\
\hline & Fatal & severi & Vinor & \\
\hline Iyth & 2 & $\xi$ & 71 & 241 \\
\hline 1465 & 3 & 5 & $10 x$ & $4 \times 5$ \\
\hline 1464 & 4 & 7 & 47 & $38 \times$ \\
\hline $146:$ & 2 & 5 & 116 & 334 \\
\hline 1462 & 1 & $x$ & 74 & 307 \\
\hline $196 \mid$ & 2 & 5 & 62 & 249 \\
\hline 1460 & 4 & 4 & 67 & 272 \\
\hline 1454 & 0 & 4 & 46 & 20)? \\
\hline 1453 & 2 & 12 & 77 & $\pm \geq 1$ \\
\hline Total & 20) & 60 & 7117 & 240194 \\
\hline
\end{tabular}

\footnotetext{
* Unfortunately, crash vehicles were not categorized by county of registration. This means if out-of-county

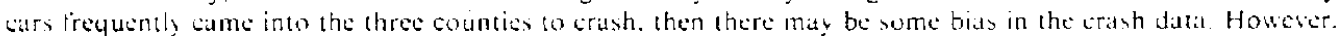
this is believed not to be a scrious laule talthough one that should be corrected in future works in view of the tindings of this report.
} 


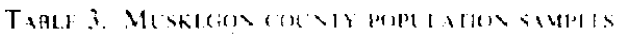

\begin{tabular}{|c|c|c|c|c|}
\hline \multirow[b]{2}{*}{$\begin{array}{l}\text { Modas } \\
\text { year }\end{array}$} & \multicolumn{3}{|c|}{ Crasiss } & \multirow[b]{2}{*}{$\begin{array}{l}\text { Control } \\
\text { population }\end{array}$} \\
\hline & $F a n a l$ & Suncte & Minur & \\
\hline $196(6)$ & 11 & $\therefore$ & 54 & 144 \\
\hline 1965: & 1 & 4 & KE & $3(1)$ \\
\hline lynt & $i$ & 4 & hI & 294 \\
\hline 196: & $\therefore$ & $\therefore$ & 75 & $24 k$ \\
\hline $146=$ & 1) & 5 & 70 & $2 \times ;$ \\
\hline 1961 & 4 & 7 & $6 i$ & 19?2 \\
\hline $14(x)$ & 2 & 5 & 56 & 23 \\
\hline 1954 & 2 & 4 & 37 & $1 \times 3$ \\
\hline 1458 & 3 & y & $y 7$ & 344 \\
\hline Tolal & 17 & 4.4 & 6114 & 2427 \\
\hline
\end{tabular}

TaHLI 4. WASHTENAW (OACTY POPTIAHON SAMPIS

\begin{tabular}{lcccc} 
Model & \multicolumn{5}{c}{$\begin{array}{c}\text { Crashes } \\
\text { Year }\end{array}$} & Fatal & Severe & Ninor & $\begin{array}{c}\text { Control } \\
\text { population }\end{array}$ \\
1966 & 7 & 10 & 56 & 336 \\
1965 & 4 & 9 & 76 & 658 \\
1964 & 7 & 11 & $6 ?$ & 525 \\
1963 & 4 & 11 & 37 & 433 \\
1962 & 1 & 8 & 32 & 342 \\
1961 & 1 & 5 & 28 & 241 \\
1960 & 3 & 3 & 37 & 256 \\
1959 & 2 & 3 & 21 & 184 \\
1958 & 1 & 9 & 28 & 391 \\
& 35 & 69 & 382 & 3356 \\
\hline
\end{tabular}

TABLF 5. 3-COLNTHS MOPLTATION SNMPIIS

\begin{tabular}{|c|c|c|c|c|}
\hline \multicolumn{5}{|c|}{ Crashes } \\
\hline $\begin{array}{l}\text { Model } \\
\text { year }\end{array}$ & Fatal & Severe & Minor & $\begin{array}{l}\text { Control } \\
\text { population }\end{array}$ \\
\hline 1966 & 10 & 18 & 185 & 777 \\
\hline 1965 & 13 & 18 & 270 & 1449 \\
\hline 1964 & 12 & 22 & 225 & 1207 \\
\hline 1963 & $\bar{y}$ & 14 & 218 & $10=4$ \\
\hline $196 ?$ & 2 & 21 & 176 & 932 \\
\hline 1961 & 7 & 18 & 158 & 710 \\
\hline 1960 & $y$ & 17 & 160 & $7 \mathrm{SI}$ \\
\hline 1959 & 4 & 11 & 104 & 576 \\
\hline 1958 & 6 & 30 & 202 & 1206 \\
\hline Total & 72 & 174 & 1698 & 8642 \\
\hline
\end{tabular}




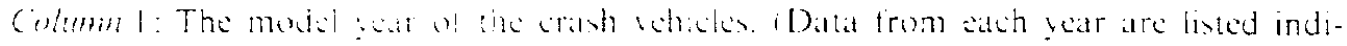

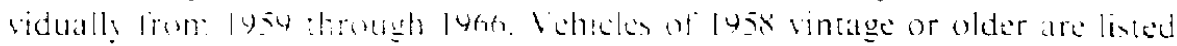
logether is $\therefore \quad 1$

Colmm 2: The age distribution of tatal crash vehicks. Tha complese poputation generaled during the sud: tome trams.

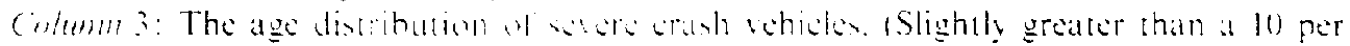
con sample?

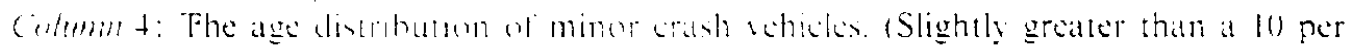
cent sample.

Collmm : : The age distributan of the sethick population which produced the erash

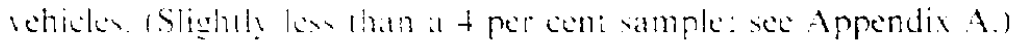

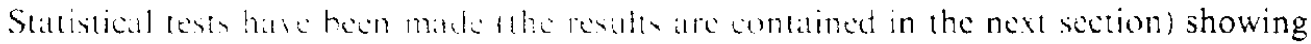

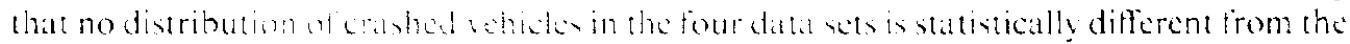
parent population trome whith a was drawn. Although the most important inferences are to be drawn from the limeng. some repesentate datal plots mas prove helptul to the

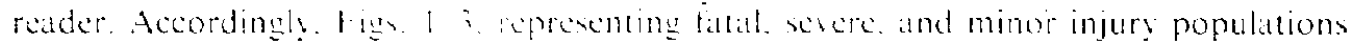
respectively. are plated at this point in the report. Since no statistically different trends

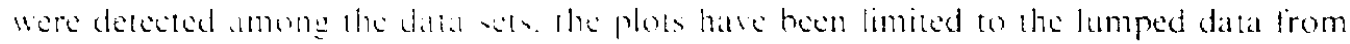
the these countich.

Before these figurs are discussed, the parameter plotted must be defined. The data in

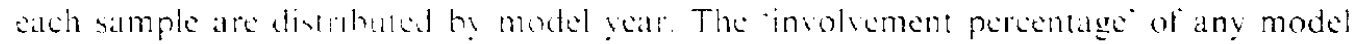

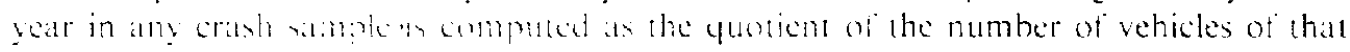
model vear divided by the lotal number of vehicles in the crash sample: the "control percentage" of any muse sar in a control vehick population may be computed similarly.

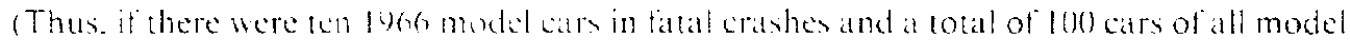

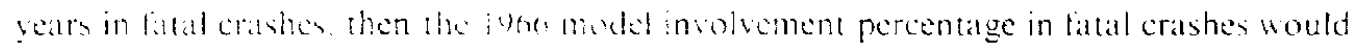

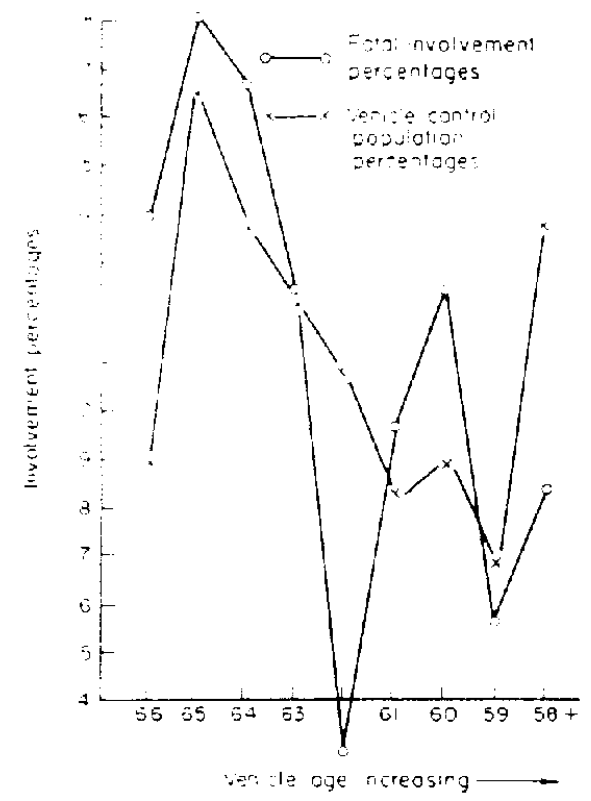

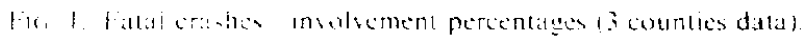




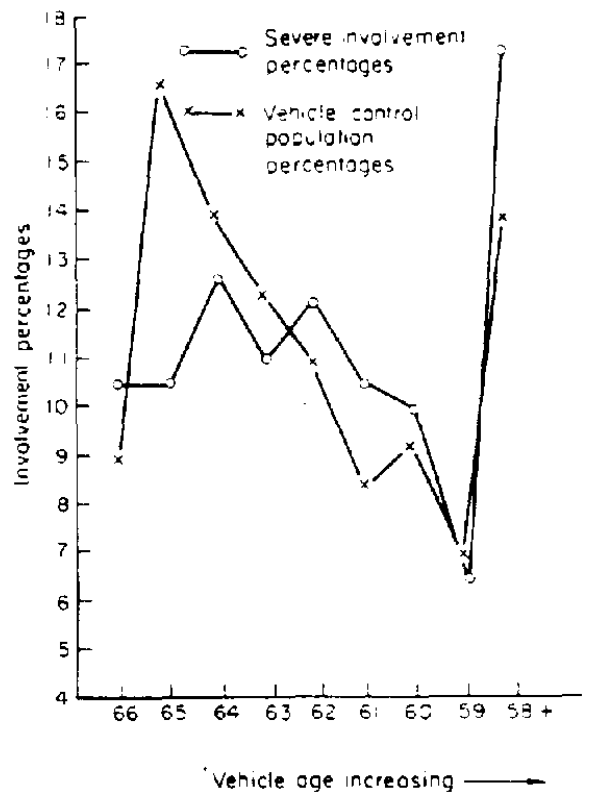

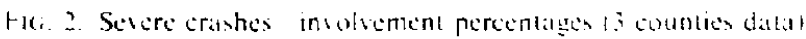

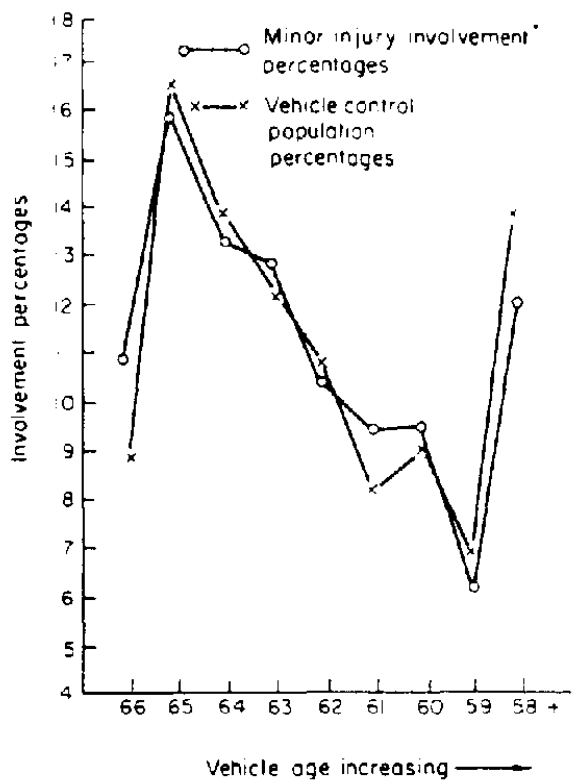

Fig. 3. Minor crashes involvement percentages 13 counties dala)

be 10 per cent.) Having generated such percentages, one can compare the trend of crash involvement with the control populations by reference to Figs. 1, 2 and 3 which plot involvement percentages and control percentages together (fatal crashes. severe crashes and minor crashes, respectively). Figure 4 shows the involvement percentages for all three severity classes plotted together. (Table 6 contains the dita plotted in Figs. $1-4$.) 


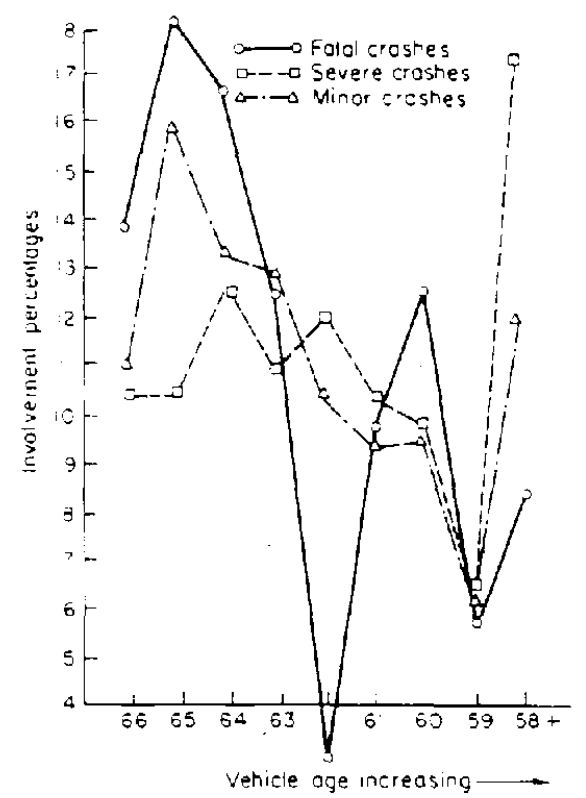

Fici. 4. Comparison of involvement percentages li countien datal.

For any age (model year) in which the crash involvement percentage exceds the control percentage. vehicles of that age are over-represented in the crash population. Likewise. vehicles of a given age are under-represented in the crash population when the control percentage exceeds the crash involvement percentage. (One could divide the two percentages to produce an "over-representation" ratio: however. since the crash populations are not statistically different from the control populations. such ratios might be misleading in these cases.)

Two observations about these figures are worth making. One is that the involvement percentages of fatal and severe crashes are much less stable with respect to the parent population than are the minor crashes. This greater stability for the minor crashes is probably a product of the larger samples. The second is that the crash involvement percentages (particularly for the minor crashes) trace the parent population with remarkable precision.

DATA ANALYSES

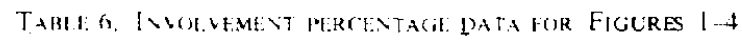
(3) ( $)$ NIF:

\begin{tabular}{|c|c|c|c|c|}
\hline \multirow{2}{*}{$\begin{array}{l}\text { Model } \\
\text { year }\end{array}$} & \multicolumn{4}{|c|}{ Involvement percentages } \\
\hline & Fatal & Severe & Minor & $\begin{array}{l}\text { Control } \\
\text { population }\end{array}$ \\
\hline 1966 & $13 \cdot 84$ & $10 \cdot 34$ & 10.89 & $x \cdot 83$ \\
\hline 1965 & 1800 & 10.34 & 15.40 & 16.56 \\
\hline 1964 & 16.67 & 1264 & 13.25 & $13 \times 82$ \\
\hline 1963 & $12 \cdot 50$ & 10.92 & 1284 & 1215 \\
\hline $196 ?$ & 2.78 & 12.07 & $10 \cdot .36$ & $10) \cdot 71$ \\
\hline 1461 & 9.72 & $10 \cdot 34$ & $4 \cdot 31$ & 8.18 \\
\hline 1960 & 1250 & 9.77 & $9+2$ & $9 \cdot 10 !$ \\
\hline 1959 & 5.50 & 63 & 6.12 & 6.65 \\
\hline 1958. & 8.33 & 1724 & 11.90 & 13.932 \\
\hline
\end{tabular}


The a nalyses were designed to detect aging phenomena associated with vehicles involved in crashes. Two suspected phenomena were: (1) given that crashes occur to vehicles of all atges, the population of vehicles involved in more serious crashes is likely to differ in age characteristics: and. (2) the age distribution of the crash population is likely to differ from the age distribution of the parent population from which it is drawn.

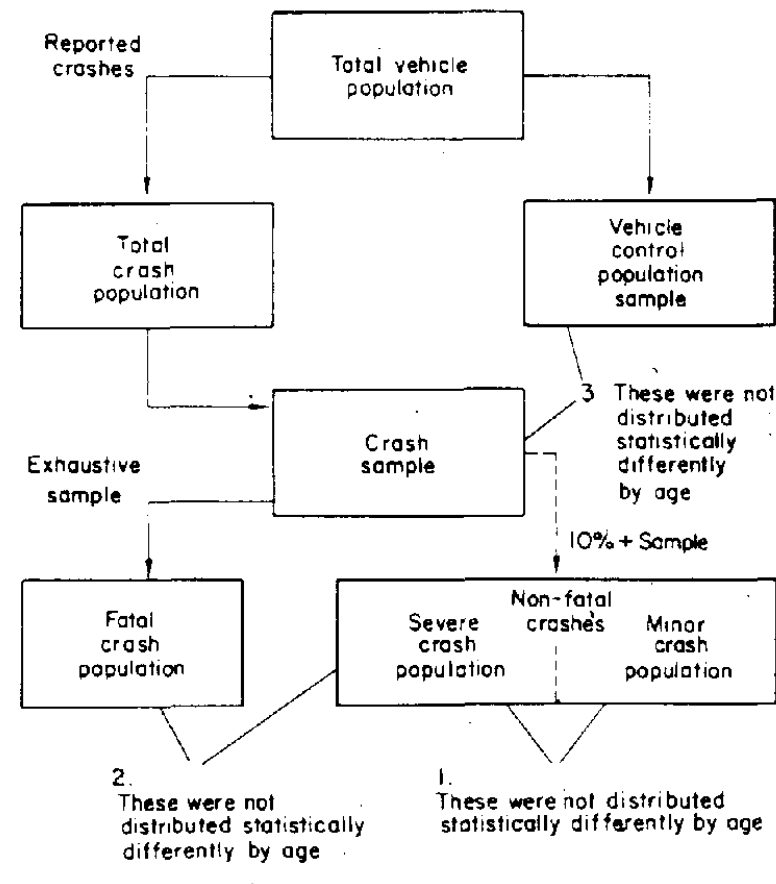

Fisi. 5. Sampling and analytical schemes.

The analytical scheme followed may be explained easily by reference to Fig. 5. (The data irom each of three counties and the lumped data have been organized separately and analyzed as described here.) The populations of the three crash samples (fatal. severe, and minor) were tested to determine whether they are distributed differently with respect to age. (For reasons to be explained. first the two non-fatal populations were compared: then they were lumped and compared with the fatals.) Next. it was planned to compare cach crash population with the sample drawn from the total vehiclë population to test for differences in the age-distributions. However. as we shall see. because the crash samples did not differ. it was only necessary to compare the non-fatal crash population to the control population sample.

Had aging phenomena been detected. over-representation ratios would have been computed and used to show how the phenomena vary with age. Even though the results of the analyses showed that over-representation ratios from these data are not statistically different from one. the concept is important and has been retained in the following discussions.

\section{ASSOCIATION OF CRASH SEVERITY AND VEHICLE,AGE}

The basic question under investigation in this section is: given that an accident has occurred. is there any detectable association between vehicle age and severity of injury sustained by the occupants? 
Let us denote the probability that vehickes of age $i(A)$ are involved in crashes of severity $j(S)$ by $\operatorname{Pr}\{A, S . C$ Cash $\}$. If age and severity are independent. this probability can be written as $\operatorname{Pr}\left\{S_{i}\left|C r a s h \quad \operatorname{Pr} A_{i}\right|\right.$ Crash That is the joint probability of severity and age is equal to the product of the marginal probabilities of these factors. The crash sitmples will be used to test the hypothesis of independence between age and severity.

Crash-involved vehicles are classitied by vehicle ange and severity of the most severe injury suffered in the vehicle. Vehicle age has been estimated by the model year of the vehick and severity has been assigned from one of the three clasitications: fatal crashes. severe erashes. or minor crashes.

The non-iatal crash data were collected by taking a ten per cent stratifed systematic sample from the three counties. Bivariate frequency tables for vehicle age versus crash severity hate been presented in Table 7 .

The $x^{2}$ test. documented in statistical texts such as Hogg and Craig (1965). is commonly used to test for association in such contingency tables, and it has been used here to test the null hypothesis of independence between the minor crash distributions and the severe crash distributions shown in these Tables. In all cases. the attained $\chi^{2}$ statistic was less than that required for rejection of the null hypothesis at a 0.05 level of significance. (All cases in this study had 8 degrees of freedom, requiring $\chi^{2}-15 \cdot 5$ for significance at the 0.05 level.) This leads one to infer that once a non-fatal crash occurs. the severity does not vary significantly with the age of the vehicles in the populations.

Fatal crash data were collected by exhaustively sampling fatal accidents occurring during the sample time frame in all three counties. Although strictly spaiking these data are not samples inasmuch as all the cases in a county are included, they have been treated as random samples from some larger geographical region and or longer time frame. It was then asked whether the age distribution of fatal crash vehicles is difterent from the age distribution of non-fatal crash vehicles. Again. $\chi^{2}$ tests have been used to test the hypothesis that these multinominal distributions are not different. The samples and resulting $\chi^{2}$ statistics are presented in Table 8.

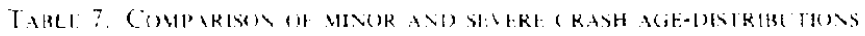

\begin{tabular}{|c|c|c|c|c|c|c|c|c|}
\hline \multirow[b]{3}{*}{$\begin{array}{l}\text { Model } \\
\text { rear }\end{array}$} & \multicolumn{2}{|c|}{ (a) } & \multicolumn{2}{|c|}{ (b) } & \multicolumn{2}{|c|}{ (c) } & \multicolumn{2}{|c|}{ (d) } \\
\hline & \multicolumn{2}{|c|}{ Mukegon } & \multicolumn{2}{|c|}{ Kalamam } & \multicolumn{2}{|c|}{ Washtenau } & \multicolumn{2}{|c|}{ S-Counties } \\
\hline & $\begin{array}{l}\text { Severe } \\
\text { crashes } \\
\text { rumber }\end{array}$ & $\begin{array}{l}\text { Minor } \\
\text { srasites } \\
\text { number }\end{array}$ & $\begin{array}{l}\text { Severe } \\
\text { erashes } \\
\text { number }\end{array}$ & $\begin{array}{l}\text { Minor } \\
\text { srashes } \\
\text { number }\end{array}$ & $\begin{array}{l}\text { Sowere } \\
\text { crathis } \\
\text { number }\end{array}$ & $\begin{array}{l}\text { Minor } \\
\text { wrishes } \\
\text { number }\end{array}$ & $\begin{array}{l}\text { Severe } \\
\text { siabes } \\
\text { number }\end{array}$ & $\begin{array}{l}\text { Minor } \\
\text { crusters } \\
\text { number }\end{array}$ \\
\hline & $\cdots$ & $\therefore$ & $=$ & $\cdot \quad--$ & i & & & \\
\hline 1966 & $\vdots$ & 5y & 5 & 71 & 111 & 56 & 18 & 185 \\
\hline 1463 & 4 & 86 & 5 & its & $\rightarrow$ & 76 & 18 & 270 \\
\hline 1460 & 4 & 61 & 7 & 97 & 11 & $6 ?$ & $\because$ & 225 \\
\hline 1463 & ; & 75 & 5 & $\ln$ & 11 & 37 & 14 & 218 \\
\hline 1962 & 5 & 70 & $s$ & 74 & $x$ & is & $2:$ & 176 \\
\hline 1301 & 7 & $6 x$ & 5 & $\therefore$ & $\vdots$ & $2 x$ & is & $15 x$ \\
\hline 1960 & $\vdots$ & ib & y & $6:$ & 3 & 37 & $1 ?$ & (nit) \\
\hline 1959 & 4 & 37 & + & 46 & $\vdots$ & 21 & 11 & 1114 \\
\hline \multirow[t]{2}{*}{ losis } & y & $4 ?$ & 12 & 77 & ) & $2 x$ & ii) & 202 \\
\hline & \multicolumn{2}{|c|}{$y^{2}+31$} & \multicolumn{2}{|c|}{$x^{2}=4 \cdot 9 !$} & \multicolumn{2}{|c|}{$\therefore 8.7$} & \multicolumn{2}{|c|}{$x^{2} \& 00$} \\
\hline
\end{tabular}




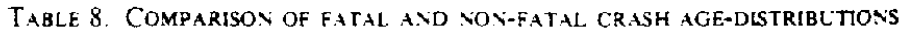

\begin{tabular}{|c|c|c|c|c|c|c|c|c|}
\hline \multirow[b]{2}{*}{$\begin{array}{c}\text { Model } \\
\text { year }\end{array}$} & \multicolumn{2}{|c|}{$\begin{array}{c}\text { (a) } \\
\text { Muskegon }\end{array}$} & \multicolumn{2}{|c|}{$\begin{array}{c}\text { (b) } \\
\text { Kalamazoo }\end{array}$} & \multicolumn{2}{|c|}{$\begin{array}{c}\text { (c) } \\
\text { Washtenaw }\end{array}$} & \multicolumn{2}{|c|}{ 3-Counties } \\
\hline & $\begin{array}{l}\text { Fatal } \\
\text { crashes } \\
\text { number }\end{array}$ & $\begin{array}{l}\text { Non- } \\
\text { fatal } \\
\text { crashes } \\
\text { number }\end{array}$ & $\begin{array}{l}\text { Fatal } \\
\text { crashes } \\
\text { number }\end{array}$ & $\begin{array}{l}\text { Non- } \\
\text { fatal } \\
\text { crashes } \\
\text { number }\end{array}$ & $\begin{array}{l}\text { Fatal } \\
\text { crashes } \\
\text { number }\end{array}$ & $\begin{array}{l}\text { Non- } \\
\text { fatal } \\
\text { crashes } \\
\text { number }\end{array}$ & $\begin{array}{l}\text { Fatal } \\
\text { crashes } \\
\text { number }\end{array}$ & $\begin{array}{l}\text { Non- } \\
\text { fatal } \\
\text { crashes } \\
\text { number }\end{array}$ \\
\hline 1966 & 0 & 62 & 2 & 75 & 7 & 66 & 10 & 203 \\
\hline 1965 & 1 & 90 & 3 & 113 & 9 & 85 & 13 & 288 \\
\hline 1964 & 1 & 65 & 4 & $104^{\circ}$ & 7 & 78 & 12 & 247 \\
\hline 1963 & 3 & 78 & 2 & 111 & 4 & 48 & 9 & 237 \\
\hline 1962 & 0 & 75 & 1 & 82 & $i$ & 40 & 2 & 197 \\
\hline 1961 & 4 & 75 & 2 & 67 & 1 & 33 & 7 & 176 \\
\hline 1960 & 2 & 61 & 4 & 76 & 3 & 40 & 9 & 177 \\
\hline 1959 & 2 & 41 & 0 & 50 & 2 & 24 & 4 & 115 \\
\hline \multirow[t]{2}{*}{$1958-$} & 3 & 106 & 2 & 89 & 1 & 37 & 6 & 232 \\
\hline & \multicolumn{2}{|c|}{$x^{2}=8.40$} & \multicolumn{2}{|c|}{$x^{2}=4.80$} & \multicolumn{2}{|c|}{$x^{2}=5.08$} & \multicolumn{2}{|c|}{$x^{2}=7.25$} \\
\hline
\end{tabular}

In all cases the data fail to yield $\chi^{2}$ statistics large enough to reject the hypothesis of no difference in the underlying populations. That is, the data show no significant differences between the age distributions of vehicles in the fatal and in the non-fatal crash vehicle populations.

In summary, no significant statistical differences have been found among the age distributions of crashed vehicles, classified according to crash severity. The implications of this will be discussed in another section. .

\section{ASSOCIATION OF CRASH OCCURRENCE AND VEHICLE AGE}

In studying the association of crash frequency with any parameter (in this case vehicle age) one attempts to estimate the probability of a crash given a particular value of that parameter. Hence, in this study $\operatorname{Pr}\left\{C r a s h \mid A_{i}\right\}$ is estimated using Bayes' Theorem expressed as:

$\operatorname{Pr}\left\{\operatorname{Crash} \mid A_{i}\right\}$

$$
=\frac{\operatorname{Pr}\left\{A_{i} \mid C r a s h\right\} \times \operatorname{Pr}\{\text { Crash }\}}{\operatorname{Pr}\left\{A_{i} \mid C r a s h\right\} \times \operatorname{Pr}\{\text { Crash }\}+\operatorname{Pr}\left\{A_{i} \mid \text { No Crash }\right\} \times \operatorname{Pr}\{\text { No Crash }\} .}
$$

A more useful form of this expression may be obtained by transforming these probabilities to odds, where the odds in favor of any event $A$ are: $\operatorname{Pr}(A) /[1-\operatorname{Pr}(A)]$. After some manipulation, the above expression becomes:

$\operatorname{Odds}\left\{\right.$ Crash $\left.\mid \mathbf{A}_{j}\right\}=\frac{\operatorname{Pr}\left\{\mathbf{A}_{i} \mid \text { Crash }\right\}}{\operatorname{Pr}\left\{\mathbf{A}_{i} \mid \text { No Crash }\right\}} \times$ Odds $\{$ Crash $\}$.

Thus, the odds in favor of a crash, given vehicle age $i$, are equal to the "likelihood ratio" of vehicle age in the crash and non-crash populations times the prior unconditional odds in favor of an accident. This is a most useful representation, for the "likelihood ratio" 
for "over-representation ratio") is exactl the "weight" by which knowledge of" whicle age increases our estimate of the probability lottst of at arash.

Hence. an over-representation ratio grealter than 1 for a given vehicle age indicates that the odds in fiavor of a crash are increated. A ratio eyual to 1 indicates no change

Since only a sample from the crash and non-crash populations tine control sample described earlier) is available. over-representation ratios can only be estimated from our data. Therefore before attaching meaning to them. the datia should be tested to determine whether these crash populations and control populations are in lict different.

Since the data come from multinomial populations. the $\chi^{2}$ test has again been used to test whether the wo populations are the same. The samples and resulting $x^{\text {? }}$ statistics are presented in Table 9 . As betore. the attaned $\%$ statistics reveal no signiticant differences at the 0.05 level of significance. ${ }^{*}$ That is. no evidence has been found to reject the bypothesis that the true over-representation ratios are equal to 1.

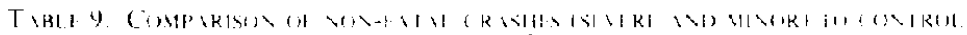

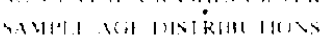

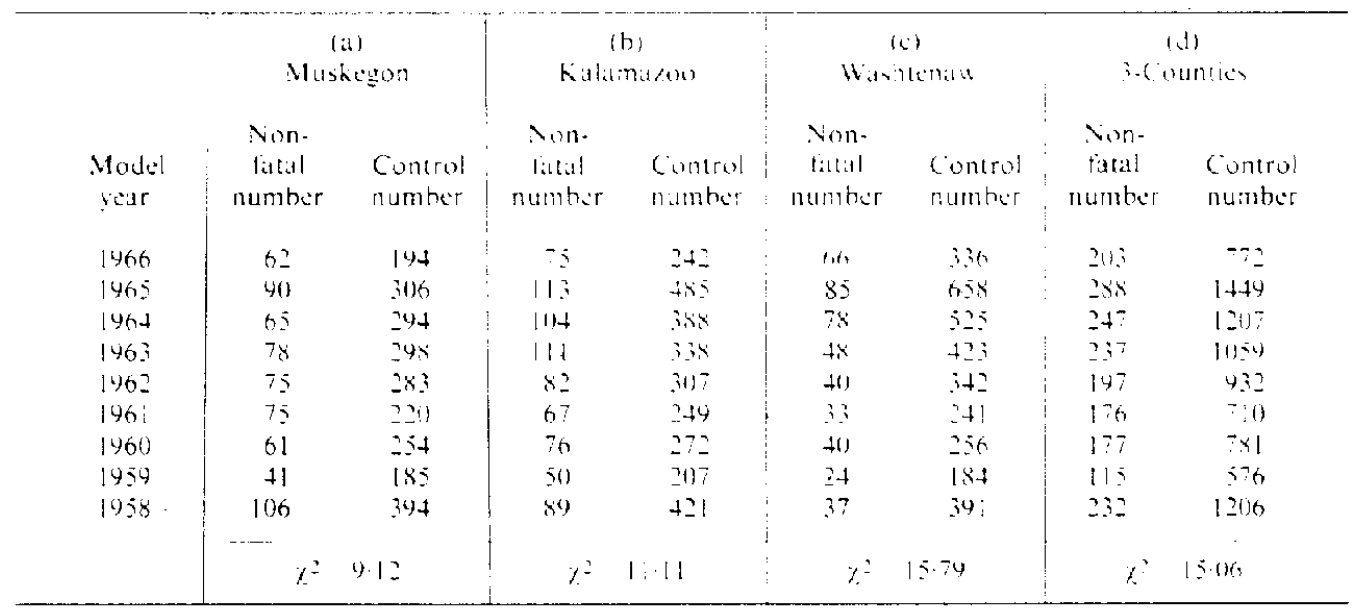

LIMITATIOVS IN DATA AVD ANALYSIS

The data are limited geographically to three counties and in time to nine months: consequently, it may not represent a random sample with respect to some larger geographical andior time population. However. no unusual disturbing variables affecting the sample obtained are suspected. so inferences might reasonably be extended to some larger population. Nevertheless. a larger sample would be desirable in validating or rejecting the results of these analyses.

In addition, although the $\chi^{2}$ tests which have been applied to the data hold strictly for asymptotic (very large) samples. practical historical experience documented by Grizzle (1967) and others suggests them to be applicable when all expected counts reach five or more. In several places in this study, counts smaller than five were obtained. especially in the fatal crash populations. Hence. a larger random sample would enhance the validity of $\chi^{2}$ tests.

* The Washtenaw County Population differences alone are just significant at the 0.05 level. However, since there is no obvious trend in the "over-representation" ratio for this county and since the pooled data reflect no significant differences, we have chosen not to analyze this further. 


\section{DISCLSSION}

With respect to the data samples included in this study. the important findings are:

(1) The populations of passenger automobiles involved in crashes (of whatever severity) and the parent vehicle populations from which they are selected are not distributed statistically differently with respect to vehicle ages. (This finding held tor the samples from each of the three counties. and for the lumped data treated as a single sample.)*

(2) When crashes involving passenger automobiles are classified according to crash severity, the populations involved in fatal crashes. severe crashes. and minor crashes are not distributed statistically differently with respect to vehicle ages. (This finding held for the samples from each of the three counties and for the lumped data treated as a single sample.)

If the findings had been different - if. for example, older vehicles had been over-represented in crashes with respect to the total vehicle population-then an inlerence that aging somehow makes crashes more likely (intuitively, through deterioration) would have been justified. From that. one might have argued in support of a program for inspecting vehicles to ensure continued mechanical soundness. These data do not support such conclusions, and, although the data do not allow one to conclude that inspecting vehicles cannot influence the potential occurrence of crashes. the findings do suggest (to the authors at least) that different phenomena should be investigated before expending resources on inspecting vehicles in hope of reducing crash and death rates.

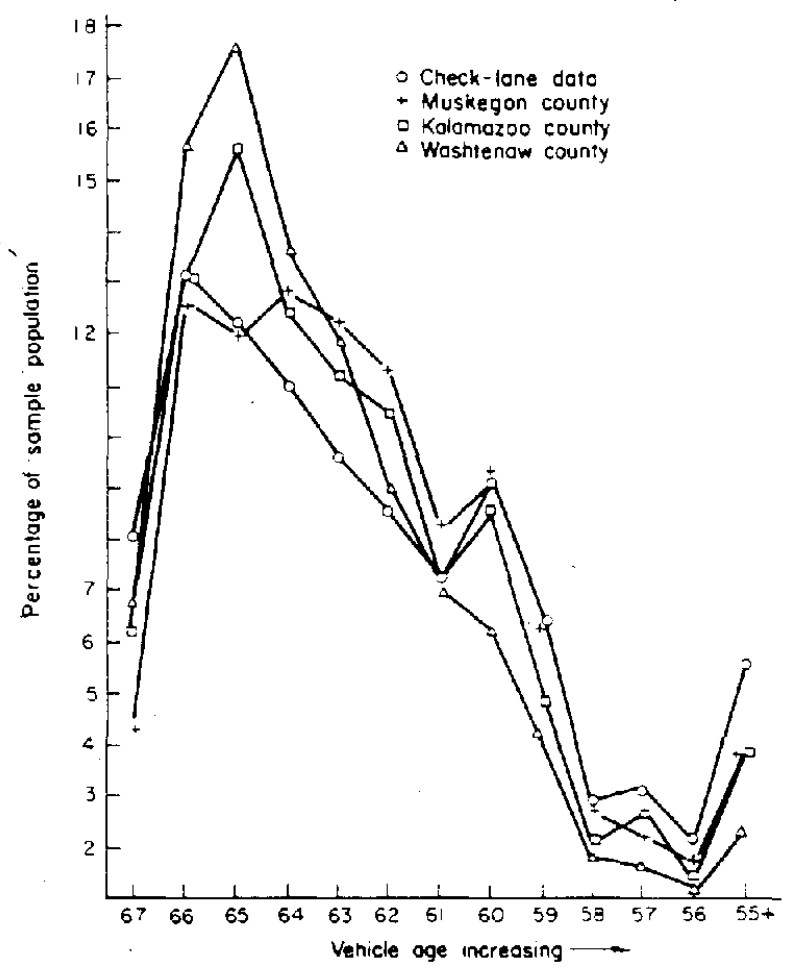

FIc. 6. Comparative vehicle population datal 11467 samples

\footnotetext{
* With the exception of the onc case mentioned in the rootnote on page 46 .
} 
On the other hand. the dalat do tend to expose as myth the notion that "old elunkers" are to hlame for a great many highwaty deaths. It anything. new vehicles maty be overrepresented in erash populations particulary tatal crast populations. Reler to Figs. 13 However. ond must bear in mind that the trendido not "prowe" over-representition. since the crash populations and the parent popudations are not statistically difierent.) A contirmation of this hypothesis would further discount recent studies. Busbaum and Colton (1966). Colton and Buxbaum (1968). and Fuchs and Leveson (1967), fatworing vehick inspections. because those studies used motor vehicle death rates as the relevant critcria. Indeed. an over-representation of newer vehicles in fatal crashes would suggest the existence of causatise lactors not likely 10 be detected by inspecting vehicles for operating detects. (These same data are being analyzed using other chatracteristics as relevant parameters in an effort to delermine whether other factors appear to be involved.)

The objections might be raised that older cars would not appear to be over-represented in crash populations because they are driven fewer miles per unit time. Certainly, if the registered older cars spend more time parked than do the newer ones. they would be less exposed to trattic hazards. The only data availabie for this study suggest this is not the case. Refer to fig. 6 showing plots of four vehicke populations: the age distributions (by model year) of the samples from the 1967 registered vehicle populations for each of the three counties in the study: and the age distribution (by model year) of the vehicle sample (32.916 vehicles) obtained by the Michigan State Police in their check-lane inspections at mutiple locations throughout the State between mid- Vareh 1967 and June 30. 1967. (A strict following of the check-lane rules should have produced a random sample dratun from the vehicles passing the inspection sites. ${ }^{*}$ )

A comparison of the distribution of the check-lane sample with that of the registered vehicle populations suggests that the age distribution of the vehicle population exposed to the check-lanes is about the same as that of the total population, but with slightly more older cars. The same over-exposure may prevail with respect to the hazards which produce crashes, although that cannot be asserted without further evidence, since the state-wide distribution producing the check-lane data could differ from the samples from the three counties. Nevertheless. on the surface the data seem to refute any notion that newer cars are likely to be over-exposed to traffic hazards relative to their numbers than are older ones.

The second. finding - given that crashes occur. the vehicles involved in the populations of fatal. severe. and minor crashes are not-distributed statistically differently with respect to atge-fails to support any notion that crashworthiness (resistance to damage once a crash occurs) deteriorates with age. By the same reasoning, it also fails to support an argument that vehicle design and manufacturing advances have entanced crashworthiness (up through the 1966 model cars). If the data had showed older vehicles to be more strongly associated with fatal and severe crashes than with minor crashes (and. pertorce, the converse for newer cars). then one would have had some evidence for promoting special

* The datis gathered during the first month (March April 467 ) in wich check-lane inspections were made in Michigan contained slightly more newer cars than indicated by the six-month totals. Conversely. the lit:er samples. as well as the six-month accumulation. showed more older cars than in the begining. Discussions with a lew sheck-lane operators suggesl that they have learned to discriminate against older cars in choosing cars for inspection from the trattic stream. Furthermore, the institution of the check-lane program particularly during its opening wecks. brought a number of "voluntecrs" who as a rule drove newer vethicles. Conseyuently. newer ears may hase been aber-represented in the carly check-tane samples and older ones over-represented in later samples. each bated on the traffic streams being sampled. 
programs aimed at maintaining crashworthiness as vehicles age in hope of reducing the severity of the crashes that occur. The data do not provide evidence supporting such an approach.

Had statistically signiticant differences been found among the various populations. over-representation ratios (defined in the preceding section) would have been computed to obtain a mathematical index of satety for vehicles of each model year. Although these findings do not justify using such an index here, the over-representation ratio concept should be useful in evaluating salety features which are added to new vehicles. For example. suppose a new crash.prevention safety feature and a new damage minimization feature are added to automobiles as of model year 1970. Then. if the features are successful. the crash experience of the population of cars equipped with them should differ from that of the population of cars not so equipped in the following ways:

1. If the safety leatures do inhibit the occurrence of crashes, then cars so equipped should exhibit lower crash involvement in the year of introduction than was exhibited by new cars introduced without the features in earlier years. To illustrate, suppose new 1969 vehicles compile an over-representation ratio greater than one during their first year in the population, and suppose the 1970 models incorporate a new crash inhibiting feature. If this feature is effective, the over-representation ratio for the 1970 models during their first year should be less than that compiled by the 1969 models during their first year.

2. If the features minimize injury upon occurrence of a crash, then of the cars so equipped involved in crashes, the proportion of serious injuries to number of crashes should be smaller than was experienced by new cars introduced without the features in earlier years.

In addition to any reduction in the number of crashes (or number per unit of exposure), over-representation ratios should be lower for new, safer cars than these ratios were for earlier (but not so safe) cars when they were new. However, since new vehicle safety standards are being implemented along with renewed emphasis on a safer highway environment. changes in over-representation ratios, when they occur. may not be discretely assignable to any one particular countermeasure. Furthermore, such procedures may be valid for evaluating countermeasures only for a few years. If new safety features were to be introduced over one or two years, and if no additional features followed for a time, after several years the entire vehicle population would be similarly equipped and in later years the safety features themselves would not affect the crash performance of new models as compared with the new models of earlier years.

\section{AFTERWORD}

In conducting the study and writing this report, the researchers have attempted to remove any biases that might lead to unjustified inferences. However, several experimental factors might affect the weight a reader would wish to assign to the conclusions. All but one have been pointed out in text, but they are listed here, so that they may be considered together.

1. The number of fatal crashes (and, in individual counties, the number of severe crashes) was sometimes smaller than would be required to establish complete confidence in the results of the statistical tests imposed.

2. Automobiles not registered in the study county in which they crashed were not removed from the crash populations.

3. The derivation of truly representative control populations is difficult, and no independent check of the quality of those produced is currently available. 
4. The data include only crashes reported to the police. Excluded were many crashes in which no injuries were suffered and in which property damage to any one car was less than $\$ 100$. Moreover. authorities believe that a lair percentage of reportable accidents are not, in fact, reported. However. they also believe that virtually all fatal and serious personal injury accidents are reported.

The authors believe that none of these factors seriously impair the validity of the basic findings. Nevertheless. if they are thought to be significant with respect to the development of salety programs. then the authors recommend that the study be repeated using larger samples and eliminating, to the extent practicable. the deficiencies mentioned above.

REFERE $\backslash$ CES

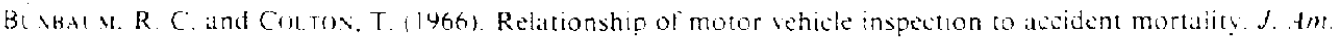
med. An. 197 iNo. 1). 101.

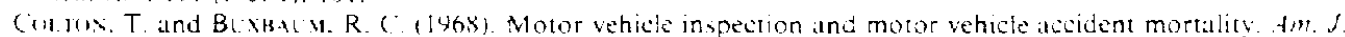
Punt. Hith. 58. 10901099

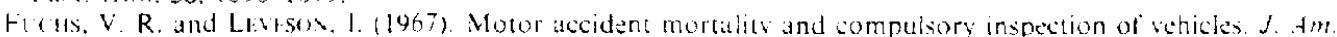
med. An. 201 iNo. Y). 87 .

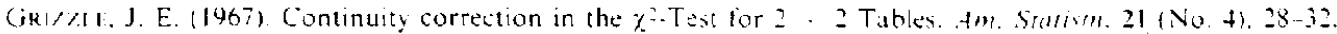

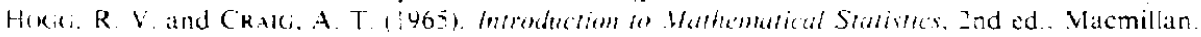

So hrtimik. R. J. and So hactrk. E. M. (1962). Elfects of aging and mileage on the accident rates of wehicles Pawenger Car Design and Highuel. Satety. Association of the Aid for Crippled Children. Consumers Lnion of the U.S. Ine

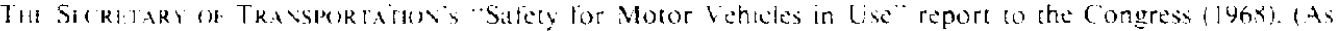
ceported in Departmenc of Transportation releatse 6068 . July 2. I 96.8

\section{APPENDIX A. CONTROL POPLLATIONS}

\section{Driving adjusted control distributions}

The age distribution of the registered passenger vehicles in each county serves as the control parameter for this study. On the surface this choice is not the most desirable. However, data are available to produce this control, whereas data for alternative controls are not.

Even though the age distribution of registered vehicles is easy to conceive of obtaining a single measurement representing a changing population over a nine-month time period is difficult. Some of the problems may be explained with reference to Fig. $\mathrm{A}-1$, which presents Washtenaw County data. (Similar figures were constructed from Kalamazoo County and Muskegon County.) The ordinate represents the control percentage of any given model year in the total sample population from which it was chosen. and the abscissa represents time in months and years. Dates of events significant to this work are presented chronologically by vertical lines as follows:

1. On about October 1 of a given year. new model year cars are introduced. The percentage of these cars in the population starts growing from zero at about this date.

2. The vehicle registration year begins with November 1 of one calendar year and ends October 31 of the next. Vehicles registered between November 1 and December 31 appear in the registration files bearing the date of the next calendar year.

3. January I marks the beginning of the period during which crashes represented in this study occurred.

4. The last day of February is the day on which registrations under the preceding year become invalid. and all operating vehicles must have current registrations by this date.

5. All the original registrations accumulated between November 1 of the preceding calendar year and about May 15 (the exact date is not clear from the records) of the current 


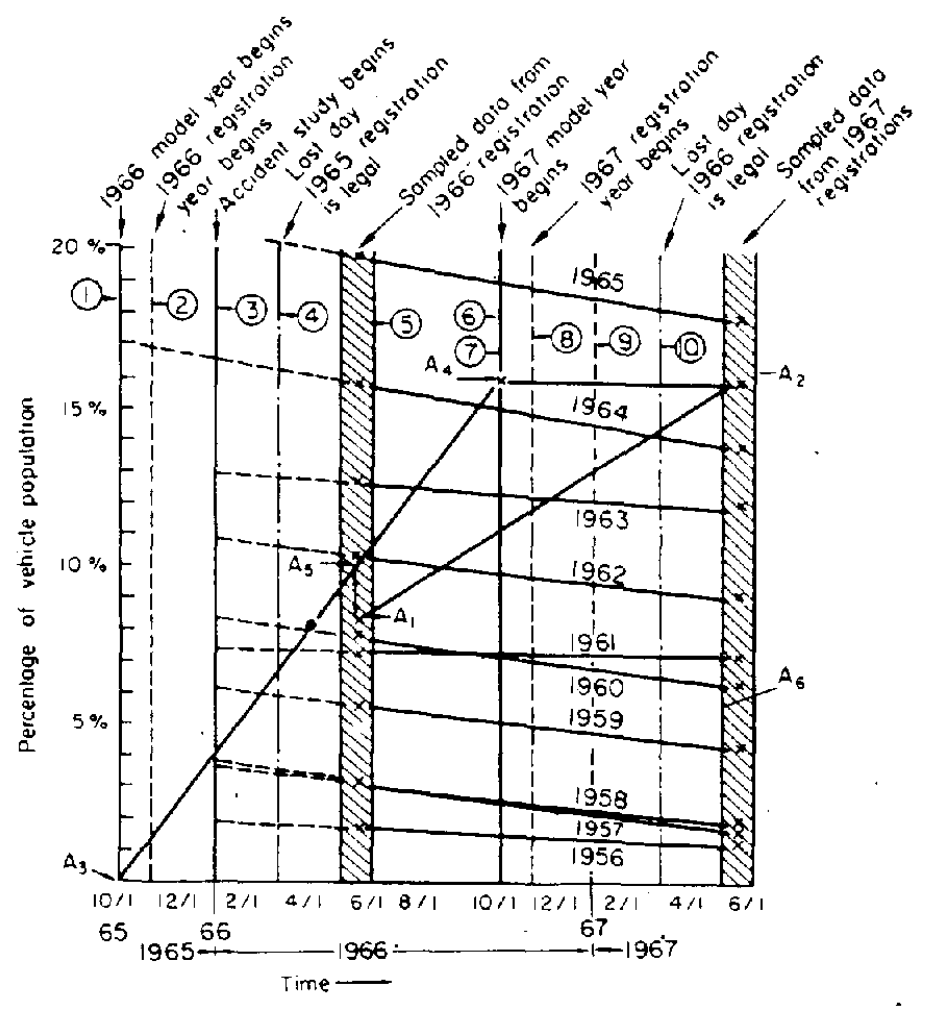

Fic: A l. Age-distribution adjustment diagram.

calendar year are published about June f. (Later registrations are filed but not published.) The shaded areas on Fig. A-1 between $5: 1$ and $6: 1$ represent the publication periods. The study population samples were drawn from the published data containing about ninety percent of the total number of original registrations for each county. Table A-I confirms that observation and shows the registration accumulation rate in the three counties.

6. To avoid including 1967 models in the study populations the study period ended with crashes occurring on September 30, 1966.

$7-8$. Recurrence of events 1 and 2 in the succeeding year.

$9-10$. Recurrence of events 3 and 4 in the succeeding year.

Figure A-l shows that the midpoint of the crash study period falls on May 15, which is about the time current year registrations are published. The published 1966 registrations are believed to understate 1966 model cars. because the publications contain only original registrations and many new cars, as they are purchased. are registered by transfer of current licenses from older cars. (In Michigan. registrations remain with the owner, not the vehicle. and when a car is traded for a different vehicle. the original registration is transferred to the second vehicle.) Therefore. it may be inferred that a number of 1966 model cars were registered by transfer* and were not represented in the published data. If so, the percentage of current model vehicles (1966) would be low. On the other hand, the

* Transfer registrations represent ahou li per cent of the total in Michigan. We do not know what proportion of the transfers are to new vehicles. 


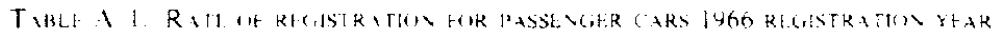

\begin{tabular}{|c|c|c|c|c|c|c|}
\hline \multirow{3}{*}{$\begin{array}{l}\text { Model } \\
\text { Yuar }\end{array}$} & \multicolumn{2}{|c|}{ Kalamaroo County } & \multicolumn{2}{|c|}{ Muskegon Counly } & \multicolumn{2}{|c|}{ Washtenau Count: } \\
\hline & & $\begin{array}{c}\text { Cumulative } \\
\text { of of }\end{array}$ & & $\begin{array}{c}\text { Cumulative } \\
\text { in of }\end{array}$ & & $\begin{array}{c}\text { Cumulative } \\
", \text { of }\end{array}$ \\
\hline & $\therefore o$ & cotal & No. & total & No. & losel \\
\hline$\cdots-$ & - & $\ldots$ & $\ldots$ & $-\ldots$ & $\ldots \ldots$ & . \\
\hline Nov 1965 & 8166 & $10 \cdot 56$ & 6466 & $10 \cdot 12$ & 10036 & $12+1$ \\
\hline Dec 1965 & 6778 & $19 \cdot 32$ & 4551 & 17.24 & 6675 & 20.71 \\
\hline Jan. 1966 & 11352 & 3400 & 8138 & $29 \cdot 98$ & 13771 & 37.33 \\
\hline Feb. 1966 & 28358 & $70 \cdot 67$ & 20877 & $67 \cdot 60$ & $2+406 ?$ & $67 \cdot 62$ \\
\hline Mar. 1966 & $1+251$ & $39 \cdot 10$ & 16196 & $88 \cdot 01$ & 16182 & $87.6 x$ \\
\hline Apr. 1966 & 1661 & 91.24 & $\mid 60) \mid$ & $90 \cdot 32$ & 1705 & $84 \cdot 80$ \\
\hline May 1966 & 1373 & 9301 & 1.329 & 9260 & 1549 & 91.72 \\
\hline June 1966 & $1: 49$ & 94.75 & 1173 & 94.43 & 1498 & $9: 5 i$ \\
\hline July 1966 & 1052 & $96 \cdot 11$ & 1046 & 9607 & 1264 & $95-14$ \\
\hline Aug. 1966 & 1121 & 47.55 & 924 & 97.52 & 1322 & $96 \cdot-8$ \\
\hline Sept. 1966 & $11+4$ & $99 \cdot 02$ & 891 & 98.91 & 1423 & 98.54 \\
\hline Oct 1966 & 716 & 100.00 & 692 & $100 \cdot 000$ & 1130 & $100 \cdot 00$ \\
\hline & 77321 & & 63884 & & 80622 & \\
\hline
\end{tabular}

percentage of 1966 model vehicles taken from the 1967 publications should be close to the true figure because almost all the 1966 models would have been introduced before the 1967 registration year and few should have left the population during their first year. This is not entirely accurate, of course, but should be very close.

Table A-2 contains the samples drawn from the published registered vehicle populations and Table $\mathrm{A}-3$ shows how large these samples are with respect to the populations from which they were drawn. The 1966 and 1967 sample data were adjusted to obtain the 1966 population age distributions which serve as the controls in this study. Table A-4 contains the adjusted distributions.

Adjustments were made as follows. First, a point $\left(A_{1}\right.$ on Fig. $\left.\mathrm{A}-1\right)$ was plotted on the vertical line through May 15. 1966, showing the control percentage of the 1966 cars in the total 1966 registration sample (data from Table A-2). Second, a point $\left(A_{2}\right)$ was plotted at May 15, 1967. showing the control percentage of the 1966 cars in the total 1967 registration sample. Third. the two points were joined by a straight line representing uniform growth of the percentage of 1966 vehicles in the total control population. (Similar points were plotted and lines drawn for other model years down to 1956. All years-with two exceptions in the Muskegon data-showed a decline from 1966 to 1967. Although the other model year plots are shown on Fig. A-1, they are not necessary for the adjusting procedure.) Fourth, it was assumed that the 1966 model control percentage began at zero as of 1 October 1966 (Point $A_{3}$ ) and grew at a uniform rate to the control percentage of that model in the 1967-registration data, as of 1 October 1966 (Point $A_{4}$ ) when the 1967 models were introduced. Points $A_{3}$ and $A_{4}$ were joined by a straight line. (Although data from the study counties are not available to validate the uniform growth rate assumption, the national rate was uniform [Fig. A-2] and no local differences are suspected.) Fifth, the 1966 model control percentage in the adjusted 1966 distribution was obtained at the intersection (Point $A_{5}$ ) of the uniform growth rate line and the vertical line drawn through May 15 , 1966. (The difference between $A_{5}$ and $A_{1}$ could be explained by the transferred registrations discussed earlier.)

Adjusting the 1966 model control percentage forced adjustments to each of the other 


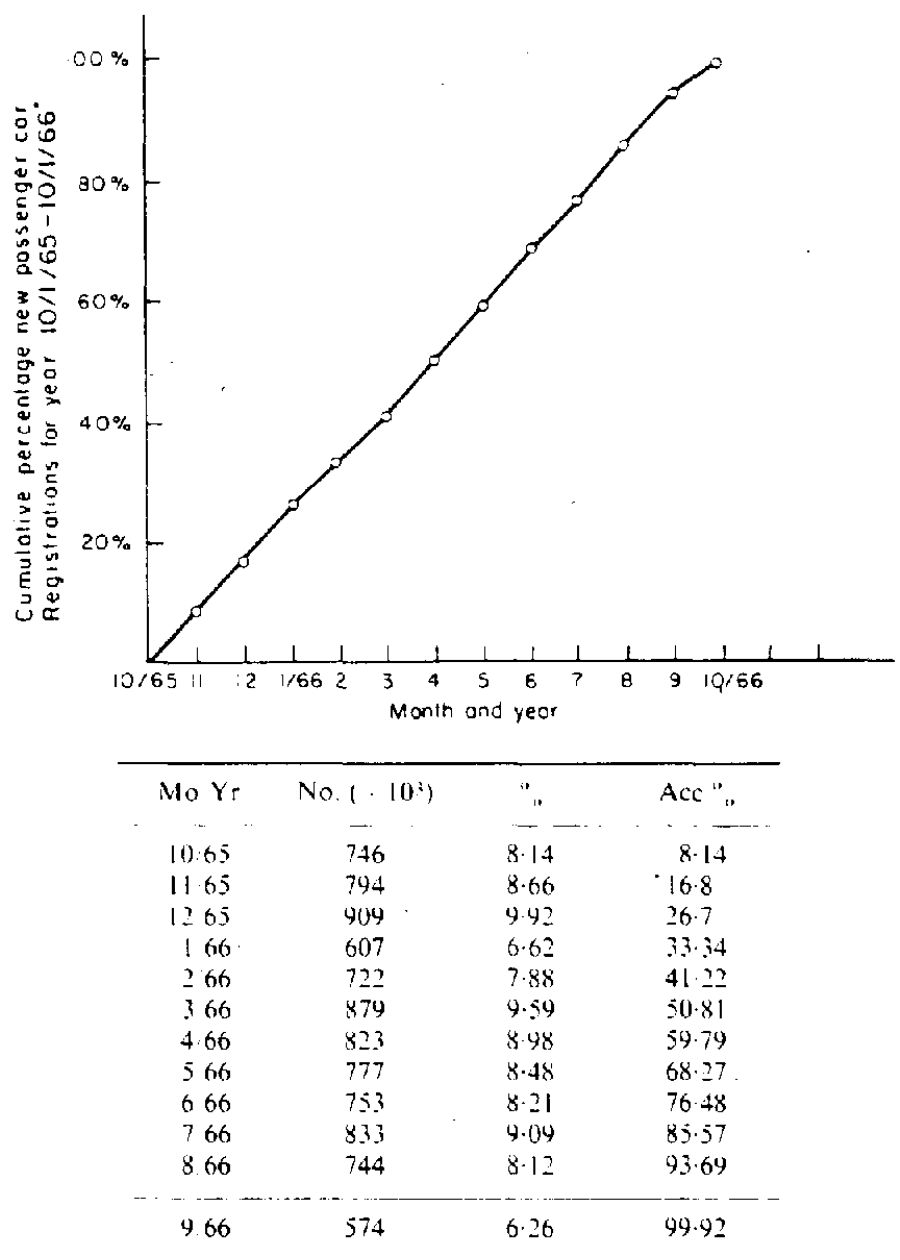

FIci. A-2. Rate of registering new passenger cars in the United States by month of year 10. $1: 65-10: 1: 66$.

model year control percentages in order to retain a sum of 100 per cent. This was done as follows:

1. Subtract the 1966 model control percentage in the registration sample from the adjusted 1966 model control percentage (obtained as outlined above). ( $A_{5}-A_{1}$ on Fig. A-1.)

2. Subtract the 1966 model control percentage in the 1966 registration sample from the 1966 model control percentage in the 1967 sample. $\left(A_{2}-A_{1}\right.$ on Fig. A-1.)

3. Add to (2) the 1967 model percentage in the 1967 registration sample. (Point $A_{6}$ plotted on the vertical line through 5 May 1967.) This sum estimates the infusion of newly manufactured cars into the population between May 15, 1966, and May 15, 1967. Since the figures are percentages, the increase for new cars must be offset by an exit of older cars from the population.

4. The number computed in (1) was divided by the number from (3) to determine the portion of the adjustment that should be applied to the remaining model year control percentages from the 1966 registration sample. Each model year control percentage was 


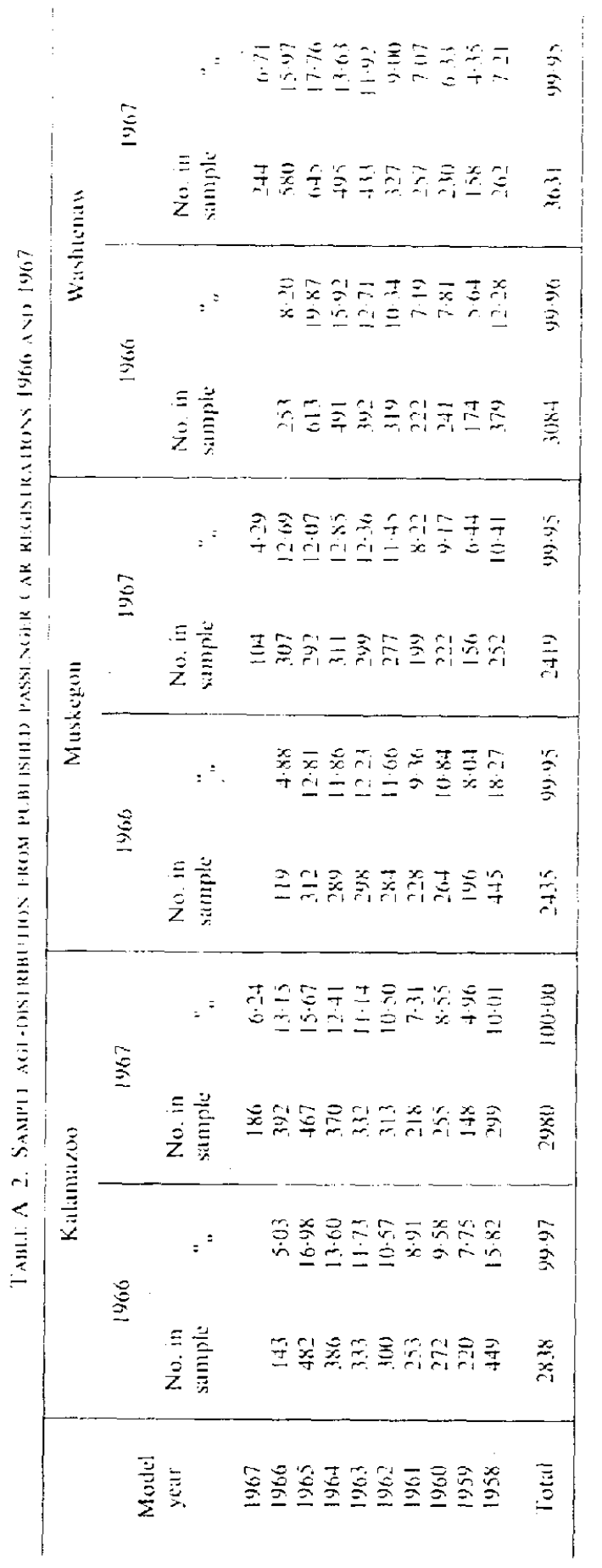




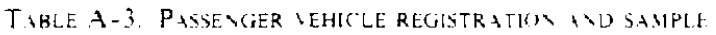
NFORMATION 1466 SERIES

\begin{tabular}{|c|c|c|c|c|}
\hline County & $\begin{array}{c}\text { Total } \\
\text { original } \\
\text { registrations }\end{array}$ & $\begin{array}{l}\text { Approximale } \\
\text { number } \\
\text { published }\end{array}$ & $\begin{array}{l}\text { Sumple } \\
\text { drulun irom } \\
\text { published dital }\end{array}$ & $\begin{array}{l}\text { Sample } \\
\text { is of original } \\
\text { registrations }\end{array}$ \\
\hline Kalamazoo & 7:3al & $7094 ?$ & 2958 & $\therefore 8 z^{\prime}$, \\
\hline Wuskegon & $638 \times 4$ & $584+0$ & 2435 & $3: 81^{\prime \prime}$ \\
\hline Washtenaw & $30 t=9$ & 3608 & $306 ?$ & $380^{\circ \prime}$. \\
\hline
\end{tabular}

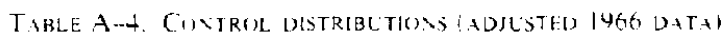

\begin{tabular}{|c|c|c|c|c|c|c|c|c|}
\hline \multirow[b]{2}{*}{$\begin{array}{l}\text { Model } \\
\text { year }\end{array}$} & \multicolumn{2}{|c|}{ Kalamazoo } & \multicolumn{2}{|c|}{ Muskegon } & \multicolumn{2}{|c|}{ Wiasheenaw } & \multicolumn{2}{|c|}{3 -Counties* } \\
\hline & $\begin{array}{c}\text { Adjusted } \\
" . "\end{array}$ & $\begin{array}{c}\text { Computed } \\
\text { number }\end{array}$ & Adjusted & $\begin{array}{l}\text { Computed } \\
\text { number }\end{array}$ & $\begin{array}{c}\text { Adjusted } \\
" .\end{array}$ & $\begin{array}{c}\text { Computed } \\
\text { number }\end{array}$ & $\begin{array}{c}\text { Adjusted } \\
\text { ". }\end{array}$ & $\begin{array}{c}\text { Computed } \\
\text { number }\end{array}$ \\
\hline 1966 & $8 \cdot 30$ & 242 & 3.00 & 194 & $10 \cdot 00$ & 336 & 8.88 & 772 \\
\hline 1965 & 16.68 & 485 & $12 \cdot 62$ & 306 & 19.61 & 658 & 16.67 & 1449 \\
\hline 1464 & $13 \cdot 33$ & 388 & $12 \cdot 11$ & 294 & 15.64 & 525 & $13 \cdot 88$ & 1207 \\
\hline 1963 & 11.60 & 338 & $12 \cdot 26$ & 298 & 12.62 & +23 & $12 \cdot 18$ & 1059 \\
\hline 1962 & $10 \cdot 56$ & 307 & 11.66 & 283 & $10 \cdot 18$ & 342 & 10.72 & 932 \\
\hline 1461 & 8.55 & 249 & $9 \cdot 07$ & 220 & $7 \cdot 18$ & 241 & $8 \cdot 16$ & 710 \\
\hline 1960 & $9 \cdot 35$ & 272 & $10 \cdot 41$ & 253 & $7 \cdot 63$ & 256 & 8.98 & 781 \\
\hline 1959 & $7 \cdot 11$ & 207 & $7 \cdot 63$ & 185 & $5 \cdot 48$ & 184 & 6.62 & 576 \\
\hline \multirow[t]{2}{*}{1958} & $14+48$ & +21 & $16 \cdot 22$ & 394 & 11.64 & 391 & $13 \cdot 87$ & 1206 \\
\hline & $99 \cdot 96$ & 2909 & 99.98 & $2+27$ & 99.98 & 3356 & $99 \cdot 96$ & 8692 \\
\hline
\end{tabular}

* These numbers are generated by summing the computed frequencies vver the three counties.

adjusted by first multiplying the ratio so obtained by the difference between the percentages (of each model year) as of 1966 and 1967. and then subtracting the product from the 1966 percentage.

Adjusted control percentages computed for each county are tabulated in Table A-4. From the products obtained and the averages of the number of data points in the 1966 and 1967 registration samples, adjusted frequency distributions by model year were calculated for each county and tabulated (Table A-4). These served as the control distributions. The three-counties distribution was obtained by summing over data from the three counties.

\section{Sampling from the registered vehicle populations}

The Michigan Department of State publishes passenger vehicle registrations in books by county (and letter prefix within a county) and each page contains a photograph of registration forms arranged in a matrix of six columns by eight rows. The first and last entry on each page was selected for the samples. making them just less than 4 per cent of the total populations. In cases of unreadable entries, the nearest readable one was taken. Model year was the only parameter extracted from the records. 